\title{
Corrigendum: Glycemia Is Related to Impaired Cerebrovascular Autoregulation after Severe Pediatric Traumatic Brain Injury: A Retrospective Observational Study
}

\author{
Adam M. H. Young ${ }^{1 *}$, Hadie Adams', Joseph Donnelly ${ }^{1}$, Mathew R. Guilfoyle', \\ Helen Fernandes ${ }^{1}$, Mathew R. Garnett ${ }^{1}$, Marek Czosnyka', Peter Smielewski ', \\ Mark Plummer ${ }^{2}$, Shruti Agrawal ${ }^{3}$ and Peter J. Hutchinson ${ }^{1}$ \\ 'Division of Academic Neurosurgery, Department of Clinical Neurosciences, Addenbrooke's Hospital, University of \\ Cambridge, Cambridge, United Kingdom, ${ }^{2}$ Neurosciences Critical Care Unit, Addenbrooke's Hospital, University \\ of Cambridge, Cambridge, United Kingdom, ${ }^{3}$ Department of Paediatric Intensive Care, Addenbrooke's Hospital, \\ University of Cambridge, Cambridge, United Kingdom
}

Keywords: brain, injury, acute, glucose, lactate

\section{OPEN ACCESS}

Edited and Reviewed by: Saskia N. De Wildt, Radboud University Nijmegen, Netherlands

*Correspondence: Adam M. H. Young ay276@cam.ac.uk

Specialty section:

This article was submitted to Pediatric Critical Care, a section of the journal Frontiers in Pediatrics

Received: 30 October 2017 Accepted: 03 November 2017 Published: 24 November 2017

Citation:

Young AMH, Adams H, Donnelly J,

Guilfoyle MR, Fernandes $H$, Garnett MR, Czosnyka M, Smielewski P, Plummer M, Agrawal S

and Hutchinson PJ (2017)

Corrigendum: Glycemia Is Related to Impaired Cerebrovascular

Autoregulation after Severe

Pediatric Traumatic Brain Injury: A Retrospective Observational Study.

Front. Pediatr. 5:245.

doi: 10.3389/fped.2017.00245
A corrigendum on

Glycemia Is Related to Impaired Cerebrovascular Autoregulation after Severe Pediatric Traumatic Brain Injury: A Retrospective Observational Study by Young AMH, Adams H, Donnelly J, Guilfoyle MR, Fernandes H, Garnett MR, et al. Front Pediatr (2017) 5:205. doi: 10.3389/fped.2017.00205

\section{MISSING FUNDING}

In the original article, we neglected to include the funder(s) for this article. We gratefully acknowledge financial support as follows. Research support: the Medical Research Council (MRC, Grant Nos. G0600986 ID79068 and G1002277 ID98489) and the National Institute for Health Research Biomedical Research Centre (NIHR BRC) Cambridge (Neuroscience Theme; Brain Injury and Repair Theme). Authors' support: PH-NIHR Research Professorship, Academy of Medical Sciences/Health Foundation Senior Surgical Scientist Fellowship and NIHR Cambridge BRC. AY is supported by an NIHR Academic Clinical Fellowship. JD is supported by a Woolf Fisher Scholarship. The authors apologize for this error and state that this does not change the scientific conclusions of the article in any way.

The original article was updated.

Conflict of Interest Statement: The authors declare that the research was conducted in the absence of any commercial or financial relationships that could be construed as a potential conflict of interest.

Copyright (๑ 2017 Young, Adams, Donnelly, Guilfoyle, Fernandes, Garnett, Czosnyka, Smielewski, Plummer, Agrawal and Hutchinson. This is an open-access article distributed under the terms of the Creative Commons Attribution License (CC BY). The use, distribution or reproduction in other forums is permitted, provided the original author(s) or licensor are credited and that the original publication in this journal is cited, in accordance with accepted academic practice. No use, distribution or reproduction is permitted which does not comply with these terms. 